\title{
PERANCANGAN APLIKASI EVALUASI KINERJA PEGAWAI DENGAN MENGGUNAKAN METODE GROUP ALGORITMA PROGRAMING
}

\author{
Design Of Employee Performance Evaluation Application Using The Group Programing \\ Algorithm Method
}

\author{
Lahmudin Sipahutar, Yan yang Thanri \\ Universitas Potensi Utama Jl. KL. Yos Sudarso, Km 6,5 No 3-A, Medan, telp/fax: (061) 6640525 \\ Jurusan Teknik dan Ilmu komputer, Universitas Potensi Utama, Medan \\ Email : mudinsipa@gmail.com, ythanri@gmail.com
}

\begin{abstract}
The company PT.Surya agroloika Reksa is a company engaged in oil palm plantations by owning private gardens in Riau province, and has 2000 employees with their respective positions. Human resources within an organization are very important to support the progress and quality of the company in achieving its goals. The foreman position at PT Surya Agrolika Reksa has shortcomings in determining the foreman's position. So far, the selection of foremen has only been based on job rankings.Applications designed with the Groub method programming algorithm will summarize several points needed in determining the foreman's position. The application will calculate these points, so the calculation process is faster and doesn't take a long time.The data collection technique used is observation by directly observing the work process carried out to obtain a clear picture of the object under study. Interviewing is conducting a direct dialogue with the authorities in providing information on the required data and studying literature by searching for literature. supporting libraries.
\end{abstract}

Keywords:PT.Surya Agrolika Reksa,Employess, Group Algoritma Programing.

\begin{abstract}
Perusahaan PT.Surya agroloika Reksa Adalah Perusahaan yang bergerak di bidang perkebunnan kelapa sawit dengan memiliki kebun pribadi yang berada di provinsi riau, dan memliki 2000 pegawai dengan jabatannya masing-masing. SDM didalam organisasi adalah hal yang penting untuk menunjang kemajuan dan kualitas suatu perusahaan dalam tercapainya suatu tujuan. pangkat mandor di PT.Surya Agrolika Reksa memiliki kekurangan dalam penentuan jabatan mandor. Selama ini pemilihan mandor hanya didasari pada rangking kerja saja.Aplikasi yang dirancang dengan metode Groub Algoritma Pograming akan merangkunm beberapa point yang diperlukan dalam penentuan jabatan mandor. Aplikasi akan menhitung point-point tersebut, sehingga proses perhitungan lebih cepat dan tidak memakan waktu yang lama. Pada penelitian ini pengumpulan suatu data yang digunakan, adalah meninjau langsung ketempatnya dengan melihat langung proses pekerjaan akan dilaksanakan agar mendapatbentuk jelas mengenaii objeck yg akan diteliti. Interviewadalah menanyakan langsung ke pada yang terkaituntukmenyampaikanrincian terhadaap suatu data yng diperlukanselanjutnya dengan mencari buku-buku yang mendukung penelitian ini.
\end{abstract}

Kunci kata :PT.Surya Agrolika Reksa,Pegawai,Group Algoritma Programing. 


\section{PENDAHULUAN}

SDM pada organisasi perusahaanadalah hal paling penting untuk menunjang kedepanan dan kualitas perusahaanuntuk mencapai suatu sasaran.Untuk nilaikepangkatan adalah suatu faktor yang paling penting bagi peningkatan karir seorang karyawan dan juga untuk mempertahankan suatu posisi kepangkatan agar dapat diduduki oleh seorang yang mempunyai kriteria yang berkompeten untuk menempati suatu kepangkatan yang diusulkan, dewasa ini yang terjadi dalam posisi jabatan tertentu itu seringkali proses kenaikan jabatan dan perencanaan karir pada perusahaan hanya didasarkan pada faktor tertentu saja, yaitu tingkat pendidikan, lamanya waktu bekerja dan golongan. Padahal belum tentu mereka yang memiliki kriteria seperti di atas itu lebih layak mendapatkan posisi pada jabatan tertentu dalam perusahaan.

Evaluasi merupakan penilaian dalam perusahaan, evaluasi dapat di artikan sebagai pengukuran akan efektifitas strategi yang di gunakan dalam mencapai tujuan perusahaan dalam evaluasi itu sendiri harus tau apa, dimana, mengapa, siapa, kapan, dan cara. Adapun yang dimaksud disini adalah evaluasi itu memiliki tahapan dalam menilai dan memutuskan masalah yang ada. Perancangan aplikasi dalam dunia komputerisasi berkembang pesat, perancangan alplikasi merupakan multimedia yang dibuat. Untuk dapat merancang konsep dalam membuat aplikasi dibutuhkan kreatifitas atau kemampuan untuk menyajikan gagasan maupun ide baru.

Transparansi proses penilaian biasanya dapat memberikan dampak positif bagi peningkatan motivasi kerja pegawai. Seperti halnya yang terjadi pada PT. Surya Agrolika Reksa. Masalah yang sering muncul saat ini adalah ketika adanya proses kenaikan jabatan berdasarkan rangking saja, sedangkan pihak manager mengalami kesulitan untuk menentukan siapa yang layak mendapatkan kenaikan jabatan, dikarenakan tidak adanya dasar-dasar nilai yang pasti untuk saat ini dan sistem pada PT. Surya Agrolika Reksa masih menggunakan Microsoft office, maka salah satu solusinya adalah menentukan siapa saja pegawai yang layak untuk berada pada posisi jabatan mandor tersebut dengan menggunakan metode GAP.

Penelitian yang berjudul "Sistem Pendukung Keputusan untuk kredit ponsel menggunakan metode SPK TOPSIS"yang dilakukan oleh peneliti hermalon dan herlan (Jurnal Ilmiah Fakultas Teknik LIMIT'S Vol.14 No 1 Maret 2018) di PT. Garasi Ponsel ini bertujuan untuk membantu memudahkan perusahaan dalam mengambil keputusan terutama jika kedatangan banyak pelanggan pada saat yang bersamaan. Penelitian ini menggunakan metode wawancara dan studi pustaka. Selain itu, sedangkan sumber data yang digunakan adalah data sekunder yaitu pengolahan data yang sudah ada di perusahaan.Berdasarkan analisis data, dapat disimpulkan bahwa kebijakan pembiayaan kredit akan mempengaruhi perputaran transaksi dan metode SPK TOPSIS akan lebih efektif dan mengurangi biaya karena dapat mengurangi tenaga kerja. Sistem pendukung keputusan ini diharapkan dapat membawa dampak yang lebih baik terhadap pertumbuhan perusahaan dengan memprioritaskan layanan cepat dan akurat.

Penelitian yang dilakukan oleh hernawati dan stefiana ( ISSN : 2087 - 2372 ) dengan judul perancangan sistempendukung keputusan penilaian kinerja pegawai menggunakan metode algoritma profile matching studi kasus : universitas nurtanio. Dengan tujuan untuk mempermudah dalam menentukan atau memberikan penilaian pada pegawai universitas tersebut, Maka dari itu dibutuhkan sistem penilaian yang akurat, jujur dan objektif serta ada tindak lanjutnya supaya bisa memotivasi pegawai untuk meningkatkan produktivitas kerja. Dalam melakukan proses penilaian kinerja pegawai, banyak kriteria yang telah ditentukan oleh instansi. Untuk memenuhi kebutuhan penilaian kinerja pegawai, penulis merancang sistem pendukung keputusan penilaian kinerja menggunakan metode algoritma profile matching dan metode penilaian diri. Dengan adanya sistem ini penilaian kinerja pegawai akan lebih efektif dan efisien.

Dalam kutipan jurnal jurnal Toroziduhu Ndruru NO ("ISSN 2301-9425") dengan judul "SPK Evaluasi Jabatan Dengan Metode Group Algoritma System". Menjelaskan bahwa metode GAP adalah salah satu solusi untuk memberikan tingkat penilaian pada proses dimana perusahaan membandingkan kinerja yang sebenarnya dengan kinerja yang diharapkan untuk menentukan apakah itu memenuhi harapan dan menggunakan sumber daya secara efektif. Kegunaan dari metode GAP adalah suatu cara untuk mengetahui peningkatan kinerja yang dibutuhkan dalam menutup kesenjangan itu. Menjadi suatuawal pengambilan suatu keputusanyang terikatoleh waktu 
dan biaya yang diperlukan agar mencapai suatu standart pelayanaan yang sudah ditentukan sertadapat mengetahuisituasi terkini dan langkah apa yang akan dilakukan dimasa mendatang.

\section{METODOLOGI PENELITIAN}

Hitungan Nilai hasil akhir

pada hasil hitungan tiap criteria tersebut kemudsin di hitubg seluruh nilai didasarkan jumlah bobot nilai dan jumlah sub criteria. Untuk hitungannya dapat ditunjukkan pada formula dibawah ini:

Nilai total (Psikolog, Kemampuan khususs $)=\underline{\text { Jumblah bobot nilai criteria }}$

Jumblah sub criteria

Hitungan Penentuan Hasil Akhir

pada Hasil akhir dsri proses ini adalah rangk dari kandidat yang di ajukan untuk mengisi suatu pangkat tertentu. Penentuan rank mengacu pada hasil hitungan tertentu. hitungan tersebut dapat di tunjukkan pada formula di bawah ini :

$H a=(X) \% N p+(x) \% N k$

catatan :

$\mathrm{Ha}$ : Hasilakhir

Np : Nila Psikologi

$N k \quad$ : NilaiKemampuan khusus

(x)\% : NilaiPersen Yang di Imputkan

Sberikut contoh pegawai dengan NPP 24006480 dari rumus di atas untuk perhitungan hasi akhir dari karyawan dengan sub kriteria dengan nilai persen $=50 / 100$ dan 50/100 Dapat dilihat pada table di bawah :

Hasilakhir $=(50 / 100 \times 2.9)+(50 / 100 \times 2.5)=2.7$

Hasilakhir $=1.45+1.25$ Hasilakhir $=2.7$

Tabel 1 Hasil keputusan

\begin{tabular}{|c|c|c|c|}
\hline \multirow{2}{*}{ Hasil Keputusan } & \multicolumn{3}{|c|}{ NPP } \\
\cline { 2 - 4 } & Darma & Agus & Feri \\
\hline $\mathrm{Np}$ & 2.900 & 2.600 & 2500 \\
\hline $\mathrm{N} . \mathrm{k}$ & 2500 & .600 & 2500 \\
\hline $\mathrm{Ha}$ & 2700 & 2717 & 2500 \\
\hline Rank & 2 & 1 & 3 \\
\hline Status & Memenuhisyarat & Memenuhisyarat & Memenuhisyarat \\
\hline catatan & Memenuhisyarat & Memenuhisyarat & Memenuhisyarat \\
\hline
\end{tabular}

Analisa Masalah

Adapun masalah padaPT. Surya Agrolika Reksa dalam evaluasi jabatan terhadap kinerja karyawan adalah sebagai berikut :

1. Ketika adanya proses kenaikan jabatan, sedangkan pihak manager mengalami kesulitan untuk menentukan siapa yang layak mendapatkan kenaikan jabatan, dikarenakan tidak adanya dasardasar nilai yang pasti.

2. Semakin banyaknya jumlah karyawan yang akan diseleksi sebagai mandor.

3. Belum adanya transparansi dalam penilaian karyawan. 
Analisa Penerapan Metode Groups AlgoritmaPrograming Analysis

Sampel yang akan diambil dalam menentukan penilaian kinerja karyawan untuk menetukan karyawan yang diajukan sebagai berprestasi adalah salah satu karyawan sebagai contoh penerapan Group Algoritma Programming (GAP) dalam menentukan penilaian kinerja karyawan tersebut. Berikut ini merupakan daftar nama dari karyawan yang akan di evaluasi jabatannya.

Tabel 2. Daftar Peserta PT. Surya Agrolika Reksa

\begin{tabular}{|c|c|l|}
\hline No & NIK & Nama Pegawai PT. Surya Agrolika Reksa \\
\hline 1 & 1200203 & Andri Sahni Boangmanalu \\
\hline 2 & 1200204 & Atok \\
\hline 3 & 1200207 & Deman Manulang \\
\hline 4 & 1200209 & Dian Marbun \\
\hline 5 & 1200222 & Niat Boangmanalu \\
\hline
\end{tabular}

Tabel 3. Penjabaran Kriteria-Kriteria

\begin{tabular}{|c|c|c|c|c|}
\hline No & Kriteria & GAP & Keterangan & $\begin{array}{c}\text { Nilai } \\
\text { Bobot } \\
\text { Kriteria }\end{array}$ \\
\hline 1. & $\mathrm{~N}_{1}$ & Pengaruh & $\begin{array}{l}1: \text { Kejujuran } \\
2: \text { Kedisiplinan } \\
3: \text { kerjasama } \\
4: \text { Sikap atau Kepribadian }\end{array}$ & $\begin{array}{l}2 \\
3 \\
4 \\
4\end{array}$ \\
\hline 2. & $\mathrm{~N}_{2}$ & Individual & $\begin{array}{l}1: \text { Kemampuan dan Keahlian } \\
2: \text { Latar Belakang } \\
3: \text { Keterampilan } \\
4: \text { Pengalaman Kerja }\end{array}$ & $\begin{array}{l}3 \\
2 \\
3 \\
3\end{array}$ \\
\hline 3. & $\mathrm{~N}_{3}$ & Ketrampilan & $\begin{array}{l}1: \text { Kecepatan Memahami } \\
2: \text { Bakat dalam belajar }\end{array}$ & $\begin{array}{l}4 \\
3\end{array}$ \\
\hline 4. & $\mathrm{~N}_{4}$ & Motivasi & $\begin{array}{l}\text { 1: hasil akhirperorang } \\
2: \text { Konsentrasi } \\
3: \text { Kesiapanuntuk capaian } \\
\text { Suatu Sasaran } \\
\text { 4: Averagehasil }\end{array}$ & $\begin{array}{l}4 \\
3 \\
4 \\
3\end{array}$ \\
\hline 5. & $\mathrm{~N}_{5}$ & Penyesuaian & $\begin{aligned} \text { 1: } & \text { Keselarasan Emosi } \\
2: & \text { Keterampilan untuk } \\
& \text { Menyelesaikan Tugas } \\
\text { 3: } & \text { Keterampilan untuk penyesuaian } \\
& \text { Diri }\end{aligned}$ & $\begin{array}{l}2 \\
3 \\
4\end{array}$ \\
\hline
\end{tabular}

Dibawah init contoh dari hitungan "gap" pda masing-masing ciri

a. Pengaruh.

Pada ciri ini, dilaksanakansuatu proses hitungan "gap"diantara profil pegawai untuk masingmasing faktor penilaian, dalam penetuan nilai dari profil jabatan yang dimilikipegawai adala ditentukan oleh perusahan tersebut. Perhitungan dapat kita lihatpada Tabl 4.3 : 
Tabel 4. Tabel "Gap” Pengaruh

\begin{tabular}{|c|c|c|c|c|c|}
\hline no & Nik & Kejujuran & Kedisiplinan & Kerjasama & Sikap \\
\hline 1. & 1200203 & 2 & 3 & 3 & 2 \\
\hline 2. & 1200222 & 2 & 3 & 3 & 4 \\
\hline 3. & 1200207 & 3 & 3 & 3 & 3 \\
\hline 4. & 1200204 & 2 & 1 & 2 & 1 \\
\hline 5. & 1200205 & 1 & 2 & 1 & 1 \\
\hline \multicolumn{2}{|c|}{ Profil } & $\mathbf{2}$ & $\mathbf{3}$ & $\mathbf{4}$ & $\mathbf{4}$ \\
\cline { 1 - 5 } Jabatan \\
\hline 1. & 1200203 & 0 & 0 & -1 & -2 \\
\hline 2. & 1200222 & 0 & 0 & -1 & 0 \\
\hline 3. & 1200207 & 1 & 0 & -1 & -1 \\
\hline 4. & 1200204 & 0 & -2 & -2 & -3 \\
\hline 5. & 1200205 & -1 & -1 & -3 & -3 \\
\hline
\end{tabular}

Dibawah ini contohhitungan "gap" untuk masing ciri

a. Pengaruh.

Pada ciri ini, dilaksanakan proses hitungan "gap"diantara profil pegawaipada masing faktor yang dinilai, pada penetuan nilai dari profil jabatan yang dimiliki pegawai adala ditentukan oleh perusahan tersebut. Perhitungan dapat kita lihatpada Tbel 4.3 :

Tabel 5 Tbel “Gap” Pengaruh

\begin{tabular}{|c|c|c|c|c|c|}
\hline no & Nik & Kejujuran & Kedisiplinan & Kerjasama & Sikap \\
\hline 1. & 1200203 & 2 & 3 & 3 & 2 \\
\hline 2. & 1200222 & 2 & 3 & 3 & 4 \\
\hline 3. & 1200207 & 3 & 3 & 3 & 3 \\
\hline 4. & 1200204 & 2 & 1 & 2 & 1 \\
\hline 5. & 1200205 & 1 & 2 & 1 & 1 \\
\hline \multicolumn{2}{|c|}{ Profil } & $\mathbf{2}$ & $\mathbf{3}$ & $\mathbf{4}$ & $\mathbf{4}$ \\
Jabatan & & & & \\
\hline 1. & 1200203 & 0 & 0 & -1 & -2 \\
\hline 2. & 1200222 & 0 & 0 & -1 & 0 \\
\hline 3. & 1200207 & 1 & 0 & -1 & -1 \\
\hline 4. & 1200204 & 0 & -2 & -2 & -3 \\
\hline 5. & 1200205 & -1 & -1 & -3 & -3 \\
\hline
\end{tabular}

\subsection{Hitungan Penentuan Rank}

Pada akhir disuatu proses "profilee matching" yaitu peringkat dri seorang akan diajukan agar mengis kepangkatan btertentu. Penerapan peringkat berpatokan kepada hasil hitungan ditunjukkan oleh formula berikut ini:

Rank $=20 / 100 \mathrm{~N}_{\text {Totall }} 1+20 / 100_{\text {Ntotall }} 2+20 / 100 \mathrm{~N}_{\text {totall }} 3+20 / 100 \mathrm{~N}_{\text {Totall }} 4+20 / 100_{\text {Ntota;1 }} 5$

Rincian:

$\mathrm{N}_{\text {Totall }} 1=$ penilaian seluruh ciri Pengaruhh

$\mathrm{N}_{\text {Totall }} 2=$ penilaian seluruh ciri Individual

$\mathrm{N}_{\text {Totall }} \mathrm{3}=$ penilaian seluruh ciri Keterrampilan

$\mathrm{N}_{\text {Totall }} 4$ = penilaian seluruh ciri Motivasii 
$\mathrm{N}_{\text {totall }} 5=$ penilaian seluruh ciri Penyelarasan

Maka dari itu cintoh sample dari formula untuk hitungan rank, lihat hasil terakhir dari pegawai dengan nik. 1200202,. Lihatt pada tbel 4.28 :

1. $\operatorname{Rank}=(20 / 100 x 4,1)+(20 / 100 x 4,4)+(20 \% x 4)+(20 / 100 x 4)+(20 / 100 x 4,15)$

Rank $=0.82+0.88+0.8+0.8+0.83$

Rank $=\mathbf{4 . 1 4}$

2. $\operatorname{Rank}=(20 / 100 \times 4,7)+(20 / 100 x 3,9)+(20 / 100 x$ 4) $(220 / 100 x 3)+(20 / 100 x 4,3)$

Rank $=0.94+0.78+0.8+0,6+0,86$

Rank $=3.98$

3. $\operatorname{Rank}=(20 / 100 x 4)+(20 / 100 x 4)+(20 / 100 x 4,75)(20 / 100 \times 3,5)+(20 / 100 x 2,9)$

Rank $=0.8+0,8+0,95+0,7+0,58$

Rank $=\mathbf{3 . 9 5}$

4. $\operatorname{Rank}=(20 / 100 \times 3,1)+(20 / 100 \times 4,5)+(20 / 100 x 3)(20 / 100 x 4)+(20 / 100 x 4,6)$

Rank $=0.62+0.9+0.6+0.8+0.92$

Rank= 3.84

5. $R$ ank $=(20 / 100 x$ 2,8) $+(20 / 100 x$ 4) $+(20 / 100 x$ 4,5) $(20 / 100 x 3)+(20 / 100 x$ 4,45)

Rank $=0.56+0.8+0.9+0.6+0.89$

Rank $=3.75$

Tabel 6. Tabel Kelompokan Bobot Nilai “Gap”ciri motivasii

\begin{tabular}{|c|c|c|c|c|c|c|c|}
\hline No. & Nik. & $\mathbf{N}_{\text {TOtaL }} \mathbf{1}$ & $\mathbf{N}_{\text {TOtaL }} \mathbf{2}$ & $\mathbf{N}_{\text {TOtaL }} \mathbf{3}$ & $\mathbf{N}_{\text {TOtaL }} \mathbf{4}$ & $\mathbf{N}_{\text {TOtaL }} \mathbf{5}$ & $\begin{array}{c}\text { Hasil } \\
\text { Akhir }\end{array}$ \\
\hline 1. & 1200203 & 4,1 & 4,4 & 4 & 3,8 & 4,15 & $\mathbf{4 , 1 4}$ \\
\hline 2. & 1200222 & 4,7 & 3,9 & 4 & 3 & 4,3 & $\mathbf{3 , 9 8}$ \\
\hline 3. & 1200207 & 4 & 4 & 4,75 & 3,5 & 2,9 & $\mathbf{3 , 9 5}$ \\
\hline 4. & 1200204 & 3,1 & 4,5 & 3 & 4 & 4,6 & $\mathbf{3 , 8 4}$ \\
\hline 5. & 1200205 & 2,8 & 4 & 4,5 & 3 & 4,45 & $\mathbf{3 , 7 5}$ \\
\hline
\end{tabular}

\section{HASIL DAN PEMBAHASAN}

\subsection{Diagraam UseCase}

Diiagram usecase menampilkan hubungan yang akan terjadidiuser dengan usecase pada system. Maka darikegunaan diiagram usecase yaitusebagai comunication. Skenario usecase perangkatSPKperusahaan adalah:

a. User yang terlibat padaEvaluasi Kinerja Pegawai ini adalah seorang manager, dan pegawai bagian SDM.

b. perangkatEvaluasi Kinerja Pegawai penempatan pegawai bisa diterapkankalausuatu user harus masuk dahulu

c. useryngsesuaibisa mauk kedalami system, sedangkan yng enggaksesuai mendapatkanketerananganerror.

d. Pengolahan data kepangkatanand datta seorang pegawaidi dapat dilakukan oleh seorang manager/pimpinan.

e. hitingan nilai dilaksanakan oleh bawahan.

Usecase diagram perangkat Sistem Evaluasi Kinerja Karyawan bisa dilihat jelas digambar dibawah ini : 


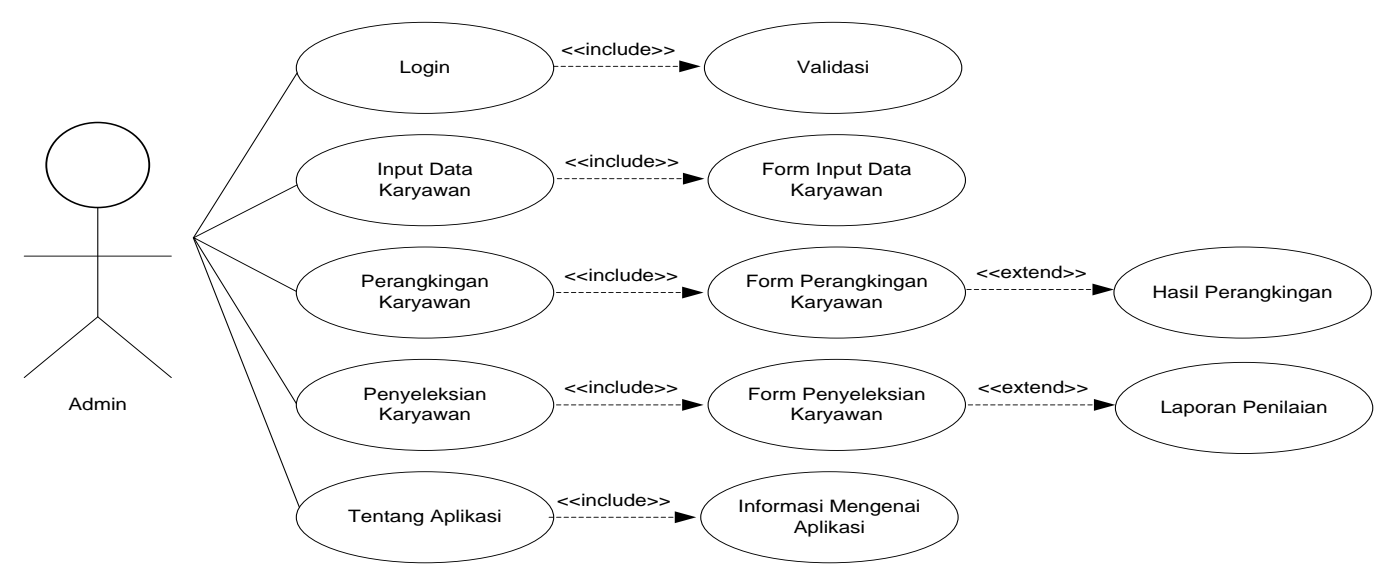

Gambar 1 Use case Sistem Evaluasi Kinerja Karyawan

Algoritma

Algoritma perancangan perangkat lunak Analisa dan Perancangan Aplikasi Evaluasi kinerja Group Algorithm Programming Analisys (Studi kasus : pada PT. Surya Argolika Reksa) dapat di dinilai darai pemetaan Gap Analysis dengan kopetensi memberikan pembobotan terhadap Gap Analysis serta perhitungan pekelompokan core dan secondary fector untuk dapat melihat perhitungan nilai total dan menjadikan penetuan perengkingan terhadap pegawai yang berprestasi.

Perancangan Metode Group Algoritma Programing

Adapun Algoritma perancangannilai total Gap Analysis yang digunakan adalah sebagai berikut :

Input :

$$
\begin{aligned}
& \text { NI } \leftarrow \text { Pengaruh } \\
& \text { N2 } \leftarrow \text { Kualifikasi } \\
& \text { N3 } \leftarrow \text { Keterampilan } \\
& \text { N4 } \leftarrow \text { Motivasi } \\
& \text { N5 } \leftarrow \text { Penyesuaian }
\end{aligned}
$$
Output : NTOTAL $\leftarrow$ Hasil Akhir Bobot Nilai GAP Rangking $\leftarrow R$

Proses :

Gap=Profile Karyawan-Profil Jabatan

$$
\begin{aligned}
& N C I=\frac{\sum N C}{\sum I C} \leftarrow \mathrm{NCI} \\
& N S I=\frac{\sum N S}{\sum I S} \leftarrow \mathrm{NSI}
\end{aligned}
$$

$60 \% \mathrm{NCI}+40 \% \mathrm{NSI} \leftarrow \mathrm{NTOTAL}$

$20 / 100 \mathrm{~N}_{\text {Totall }} 1+20 / 100_{\text {NtotallL }} 2+20 / 100 \mathrm{~N}_{\text {Totall }} 3+20 / 100 \mathrm{~N}_{\text {Totall }} 4+$ $20 / 100_{\text {NTTAL }} 5 \leftarrow \mathrm{R}$

1.4 Implementasi Perangkat Lunak

1.4.1 Spesifikasi Hardware dan Software

software ini disarankanagar dilaksanakan dengan menggunakan (hardware) yang mempunyai ciri minimal sebagai berikutt : 
1. Proseso,r Intel Pentium 4 1.6 Ghz.

2. Memoryy $128 \mathrm{MB}$.

3. Harddisk, $10 \mathrm{~GB}$.

4. VGAcard $32 \mathrm{MB}$.

5. resolusi denganMonitor768 pixel $^{*} 1024$.

6. Keyboard. dan Mouse.

Adapun perangkat (software) yang digunakan untuk menjalankan apk ini adalah lingkungan system operasi MS-Windows 97 atau MS-Windows NT/2000/XP.

Tampilan Output Perangkat Lunak

Berikut ini diberikan tampilan output dari perangkat lunak :

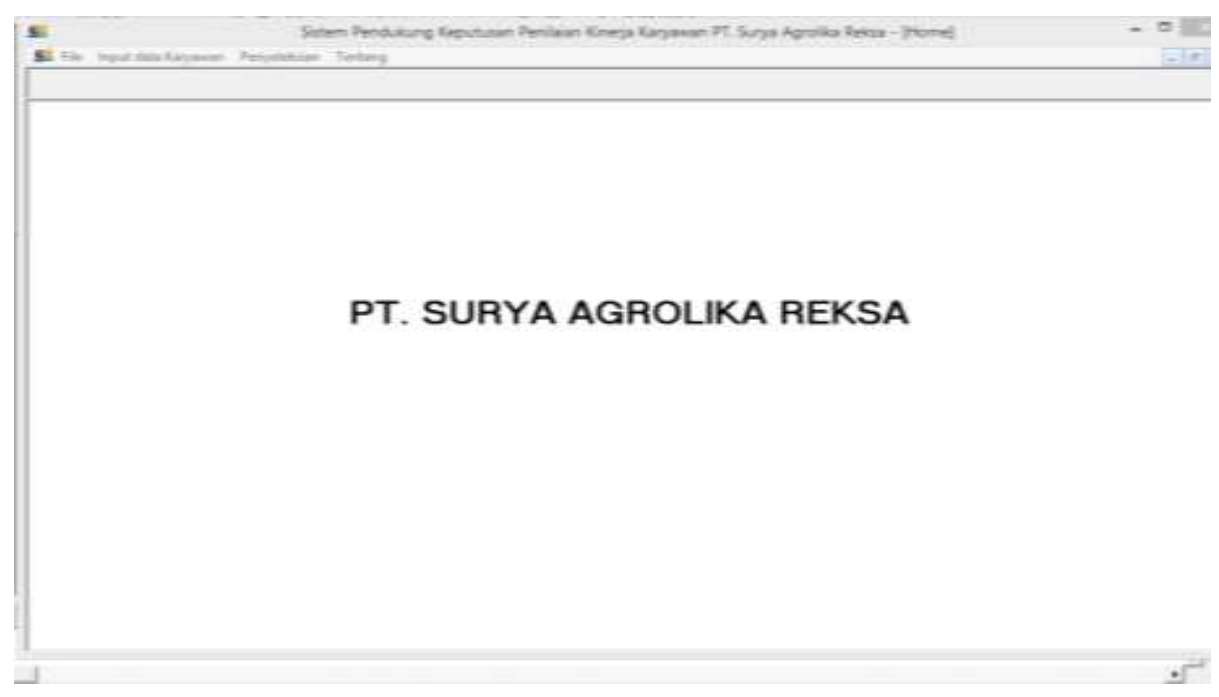

Gambar 2. From Halaman Depan

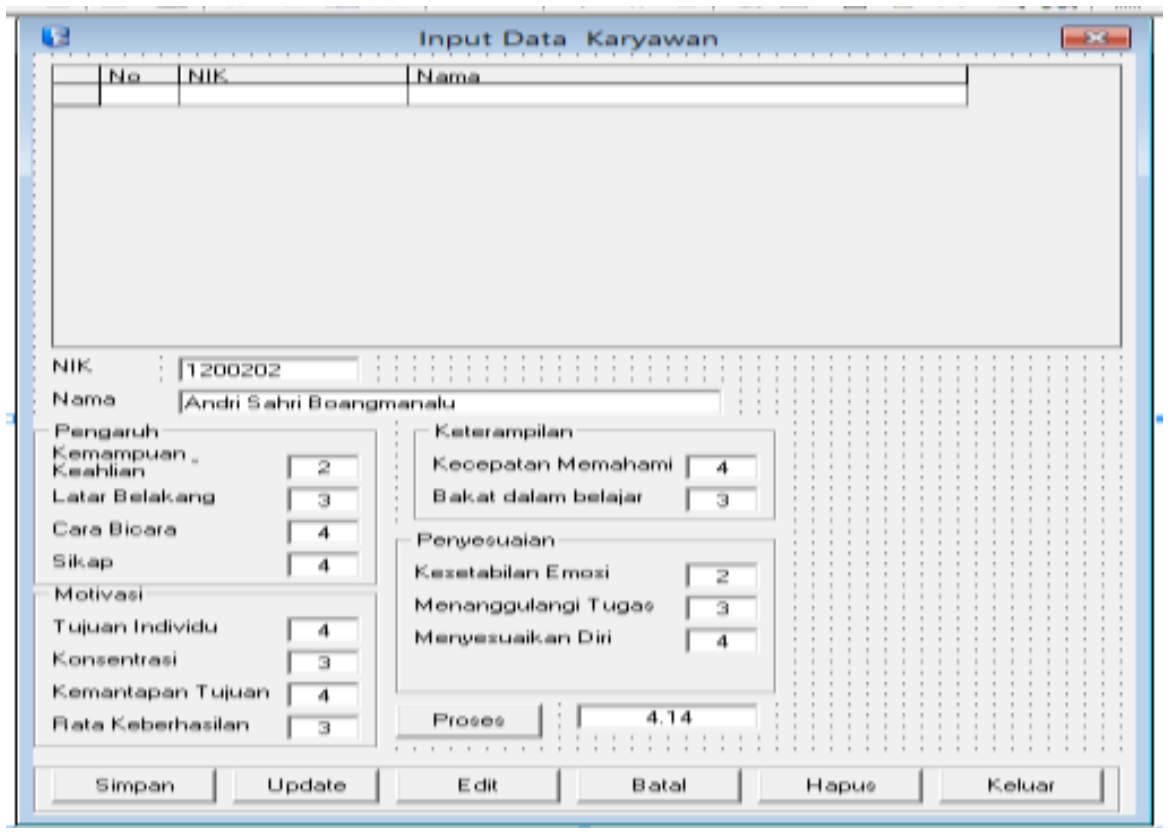

Gambar 3. From Input Data Kinerja Pegawai Berprestasi 


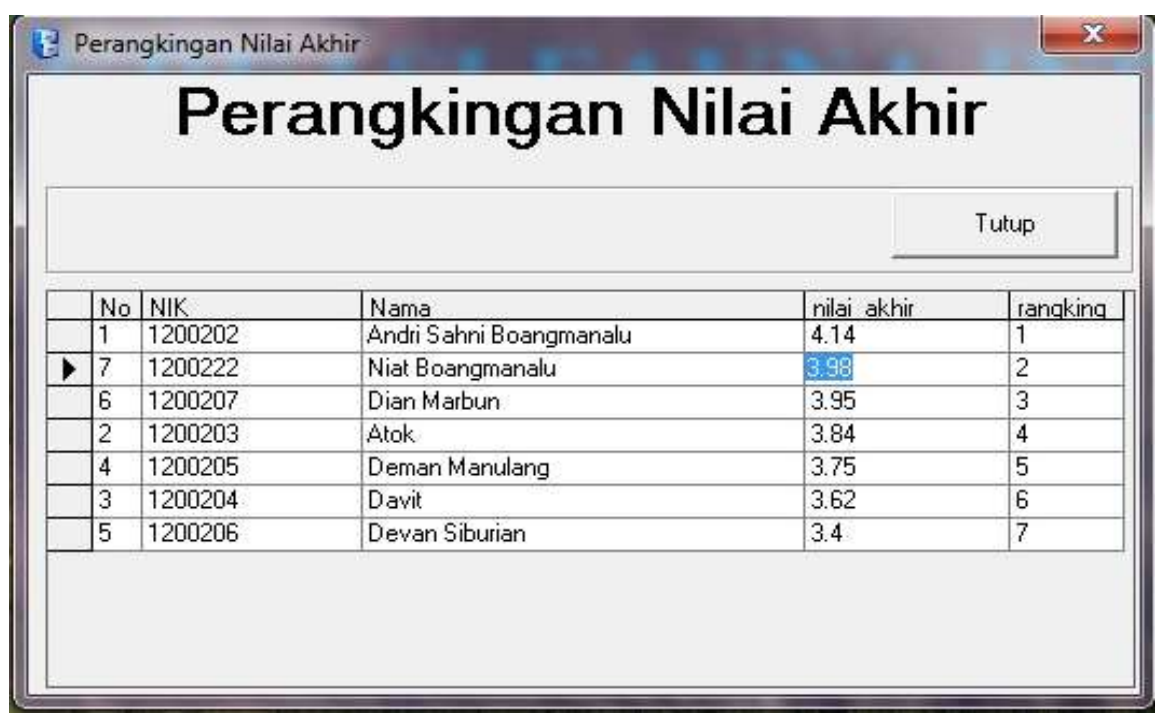

Gambar 4. From Output Proses Prengkingan Nilai Akhir Pegawai

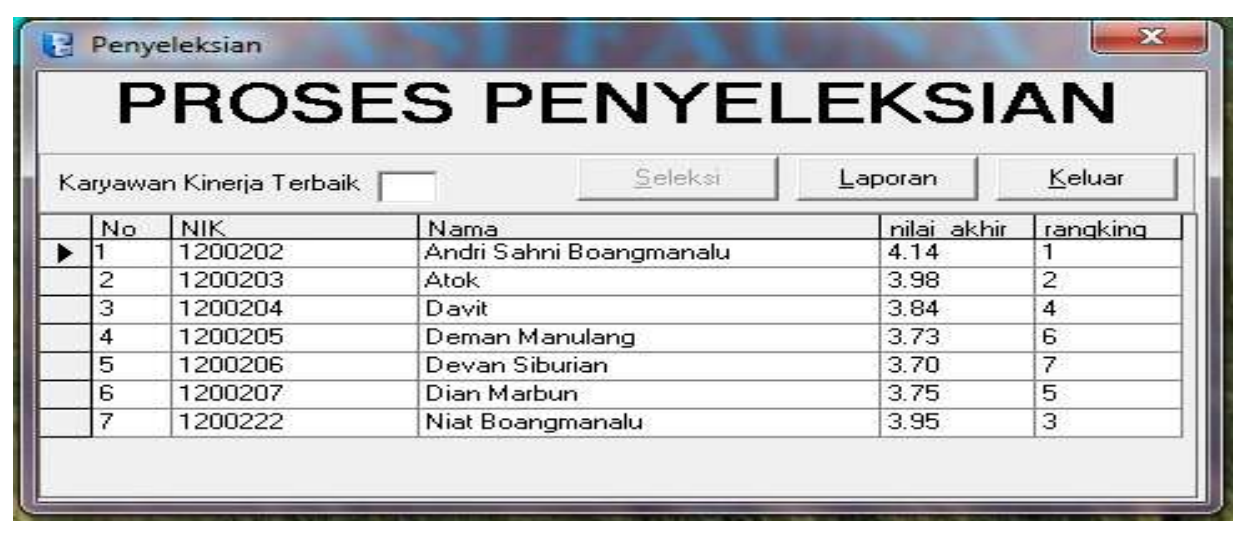

Gambar 5. From Output Proses Penyeleksian

\section{KESIMPULAN}

Dari hasil penelitian dan pembahasan, maka penulis mengambil kesimpulan sebagai berikut

1. Untuk mengetahui proses evaluasi terhadap kinerja pegawai pada PT. Surya Argolika Reksa dibutuhkan data-data yang ada pada perusahaan. Data-data tersebut dikumpulkan dan dibentuk menjadi salah satu data dalam pembuatan kriteria-kriteria untuk menilai kninerja pegawai.

2. Pengimplementasian Group Algorithm Programing Analysis dalam penilaian kinerja pegawai didalam perusahaan dimulai dari kriteria pembobotan dari pengaruh, individual, keterampilan, motivasi dan penyesuaian.

3. Untuk merancang sebuah perancangan aplikasi evaluasi kinerja pegawai kedalam sebuah sistem didalam perusahaan dapat melakukan penyelesaian penilaian presltasi kinerja pegawai diperlukan beberapa tahap yaitu dengan mengetahui Diagram Use Case perancangan aplikasi evaluasi kinerja pegawai tersebut, dan menerapkannya ke dalam suatu software/program. 


\section{SARAN}

Adapun saran dari penulis adalah sebagai berikut :

1. Informasi-informasi yang berhubungan dengan karyawan maupun jabatan dapat disimpan dalam suatu database sehingga jika suatu saat diperlukan untuk proses profile matching dapat dilakukan dengan mudah lebih mudah daripada dengan bentuk hardcopy.

2. perancangan aplikasi evaluasi kinerja karyawan ini perlu dikembangkan dengan metode : Analytic Hierachy Proses (AHP), dan lain-lain.

3. Selain menggunakan Group Algorithm Programing Analysis juga bisa dilakukan penelitian menggunakan metode yang lain sebagai perbandingan untuk mendapatkan hasil yang lebih baik.

\section{UCAPAN TERIMAKASIH}

Penulis mengucapkan terima kasih kepada pihak Universitas Potensi Utama yang telah membantu dalam penulisan ini dan tidak lupa saya juga berterima kasih kepada teman-teman saya karena sudah mendukung dalam penulisan jurnal ini.

\section{DAFTAR PUSTAKA}

[1] Wahana Komputer, "Visual Basic 2008”, Penerbit Andi, Semarang, Edisi I, 2009

[2] Anwar Prabu , "Evaluasi Kinerja SDM", Penerbit PT Refika Aditama, Bandung, Edisi I, 2005.

[3] Abdul Kadir, "Database MySQL”, Penerbit Andi, Yogyakarta, Edisi I, 2010.

[4] Jurnal : Sistem Pendukung Keputusan Evaluasi Jabatan Terhadap Kinerja Pegawai Dengan Menggunakan Metode Groub Algoritma Programing(Stdi Kasus:PT.Surya Agrolika Reksa,Toroziduhu Ndururu, 2012.

[5] Puspitasari,FikaN.2015.SistemPendukungKeputusan Penentuan Karyawan tetap Menggunakan Metode Naïve Bayes.Skripsi.

[6] Jayanti, NKDA, 2013, Implementasi Metode Bayes Pada Penilaian Kinerja Dosen, EKSPLORA INFORMATIKA Vol. 2, No. 2,Maret 2013, pp 101-108.

[7] Wibowo, AP., Hartati, S., 2016, Sistem Klasifikasi Kinerja Satpam Menggunakan Metode Naïve Bayes Classifier. INOVTEK POLBENG - SERI INFORMATIKA, VOL. 1, NO. 2, NOVEMBER 2016, pp 192-201

[8] Hani Handoko, 1995, Manajemen SumberdayaManusia,bpfe, Yogyakarta.

[9] Mulyati,SandSetiani,N.,2018,IdentifyingStudents' Academic AchievementandPerso nalityTypesWithNaiveBayesClassification.Sebatik,22(2),pp64-68.

[10] Hartono, H., Sadikin, M., Sari, D. M., Anzelina, N., Lestari, S., \& Dari, W. (2020). Implementation of Artifical Neural Networks with Multilayer Perceptron for Analysis of Acceptance of Permanent Lecturers. Jurnal Mantik, 4(2), 1389-1396.

[11] Sari, Viny N., Astri, Lola Y., and Rasywir, E., 2020. Analisis dan Penerapan Algritma Naïve Bayes Untuk Evaluasi Kinerja Karyawan Pada PT. Pelita Wira Sejahtera. Jurnal Ilmiah Mahasiswa Teknik Informatika. Vol. 2, No.1, Maret 2020.

[12] Sari,VinyN.,Astri,LolaY.,andRasywir, E.,2020. Analisis dan Penerapan Algritma Naïve Bayes Untuk Evaluasi Kinerja Karyawan Pada PT. Pelita Wira Sejahtera. Jurnal Ilmiah MahasiswaTeknik Informatika.Vol.2,No.1, Maret2020. 
